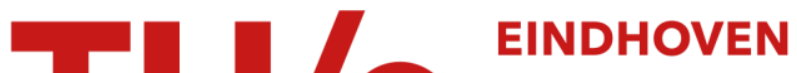 UNIVERSITY OF TECHNOLOGY
}

\section{Some future directions in computational failure mechanics}

\section{Citation for published version (APA):}

Borst, de, R., Carmeliet, J., Pamin, J., \& Sluys, L. J. (1994). Some future directions in computational failure mechanics. In G. M. A. Kusters, \& M. A. N. Hendriks (Eds.), DIANA computational mechanics : 1st international conference on computational mechanics : proceedings, Delft, 1994 (pp. 1-12). Kluwer Academic Publishers.

Document status and date:

Published: 01/01/1994

\section{Document Version:}

Publisher's PDF, also known as Version of Record (includes final page, issue and volume numbers)

\section{Please check the document version of this publication:}

- A submitted manuscript is the version of the article upon submission and before peer-review. There can be important differences between the submitted version and the official published version of record. People interested in the research are advised to contact the author for the final version of the publication, or visit the $\mathrm{DOI}$ to the publisher's website.

- The final author version and the galley proof are versions of the publication after peer review.

- The final published version features the final layout of the paper including the volume, issue and page numbers.

Link to publication

\section{General rights}

Copyright and moral rights for the publications made accessible in the public portal are retained by the authors and/or other copyright owners and it is a condition of accessing publications that users recognise and abide by the legal requirements associated with these rights.

- Users may download and print one copy of any publication from the public portal for the purpose of private study or research.

- You may not further distribute the material or use it for any profit-making activity or commercial gain

- You may freely distribute the URL identifying the publication in the public portal.

If the publication is distributed under the terms of Article 25fa of the Dutch Copyright Act, indicated by the "Taverne" license above, please follow below link for the End User Agreement:

www.tue.nl/taverne

Take down policy

If you believe that this document breaches copyright please contact us at:

openaccess@tue.nl

providing details and we will investigate your claim. 


\title{
SOME FUTURE DIRECTIONS IN COMPUTATIONAL FAILURE MECHANICS
}

\author{
R. DE BORST ${ }^{1}$, J. CARMELIET ${ }^{2}$, J. PAMIN and L.J. SLUYS \\ Delft University of Technology, Faculty of Civil Engineering, \\ P.O. Box 5048, 2600 GA Delft, The Netherlands
}

\begin{abstract}
Continuum approaches are reviewed which can properly model localised deformations that act as a precursor to final fracture in quasi-brittle materials. Next, one such higher-order damaging continuum model is combined with a stochastic approach to describe the heterogeneity in quasi-brittle materials.
\end{abstract}

Keywords: Softening, localisation, finite element analysis, random fields

\section{Introduction}

Failure in quasi-brittle and frictional materials involves localisation of deformation, i.e., we observe that at incipient failure small zones of highly strained material develop abruptly while the remainder of the body experiences virtually no additional straining. Examples are cracks in concrete, shear bands in soils and rock faults. Experiments show that these localisation phenomenona are accompanied by a sharp decrease of the load-carrying capacity. This phenomenon is commonly named strain softening and leads to ill-posed boundary value problems in standard continuum theories, since in quasi-static problems ellipticity of the governing set of differential equations is lost and in dynamic problems hyperbolicity is lost. In numerical simulations this leads to an extreme mesh sensitivity in terms of fineness and direction of the grid lines. To remedy this improper behaviour the standard continuum model must be enriched by adding higher-order terms, either spatially or in the time domain. These techniques are commonly referred to as regularisation methods. In this contribution we shall scrutinise the possibilities of using enriched continuum theories (non-local and gradient theories) to remedy this deficiency of the standard continuum. For dynamic problems the possibility of adding viscosity to the constitutive model will also be investigated. Finite element analyses are presented to illustrate some of the approaches.

1. Also at Eindhoven University of Technology, Faculty of Mechanical Engineering

2. On leave from Catholic University of Leuven, Department of Civil Engineering 
Another important property of these materials is the inherent heterogeneity at a relatively large scale. This heterogeneity may imply that the exact failure mode can be highly dependent upon the precise flaw distribution. To model this inhomogeneity stochastic material properties must be assumed in numerical simulations. However, the use of a stochastic approach does not resolve the above mentioned issue of the change of character of the governing differential equations during progressive damage. A simulation technique that describes the true failure process properly within the framework of continuum mechanics must incorporate both a regularisation of the standard continuum during progressive damage and a stochastic strength distribution. This statement will be substantiated in this contribution. To do so we will present finite element analyses of direct tension tests with a local damage model and with a nonlocal damage model. In both cases deterministic as well as stochastic calculations using a Monte Carlo technique will be presented for two different levels of discretisation. The randomness in the damage process will be introduced by considering the initial damage as a univariate homogeneous random field, describing the continuous spatial distribution and the autocorrelation.

\section{Cracking, damage and localisation of deformation}

The essential deficiency of the standard continuum model can be demonstrated simply by the example of a simple bar loaded in uniaxial tension [1]. Let the bar be divided into $m$ elements. Now suppose that one element has a tensile strength that is marginally below that of the other $m-1$ elements. Upon reaching the tensile strength of this element failure will occur. In the other, neighbouring elements the tensile strength is not exceeded and they will unload elastically. The result in terms of the displacement of the end of the bar is fully dominated by the discretisation, and convergence to a 'true' post-peak failure curve does not seem to occur. In fact, it does occur, as the failure mechanism in a standard continuum is a line crack with zero thickness. The finite element solution of our continuum rate boundary value problem simply tries to capture this line crack, which results in localisation in one element, irrespective of the width of this element. The result on the load-average strain curve is obvious: for an infinite number of elements $(m \rightarrow \infty)$ the postpeak curve doubles back on the original loading curve. Numerous numerical examples for all sorts of materials exist which further illustrate the above argument. From a physical point of view the above behaviour is unacceptable and when we adhere to continuum descriptions one must enrich the continuum by adding higher-order terms, either in space or in time, which can accommodate narrow zones of highly localised deformations.

\subsection{The fracture-energy 'trick'}

As an intermediate solution between using the standard continuum model 


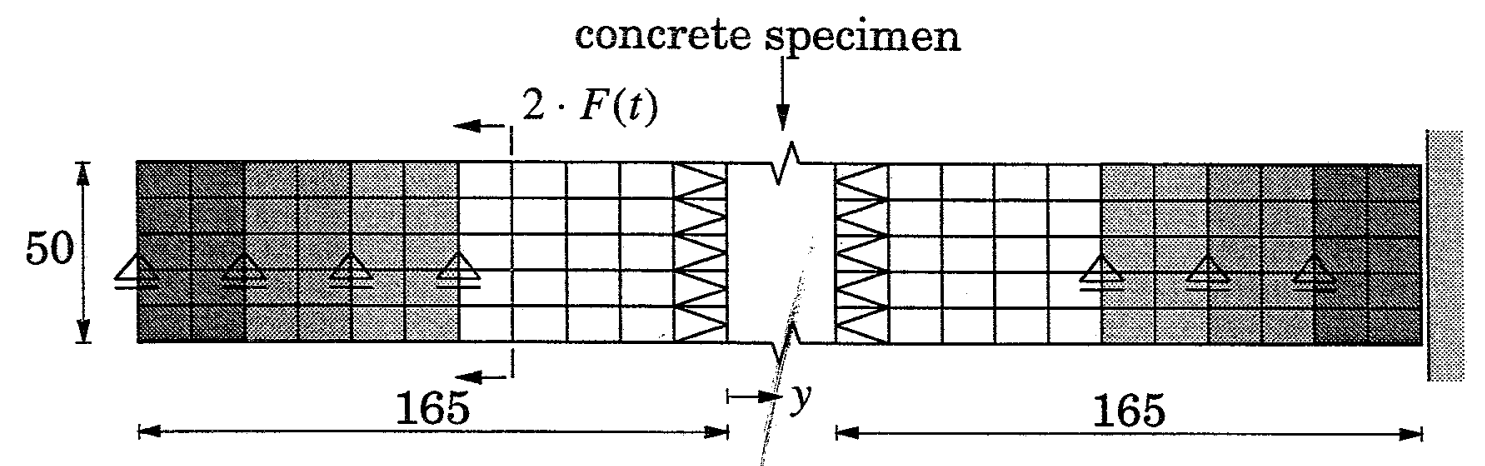

Fig. 1. Numerical model of Split-Hopkinson bar.
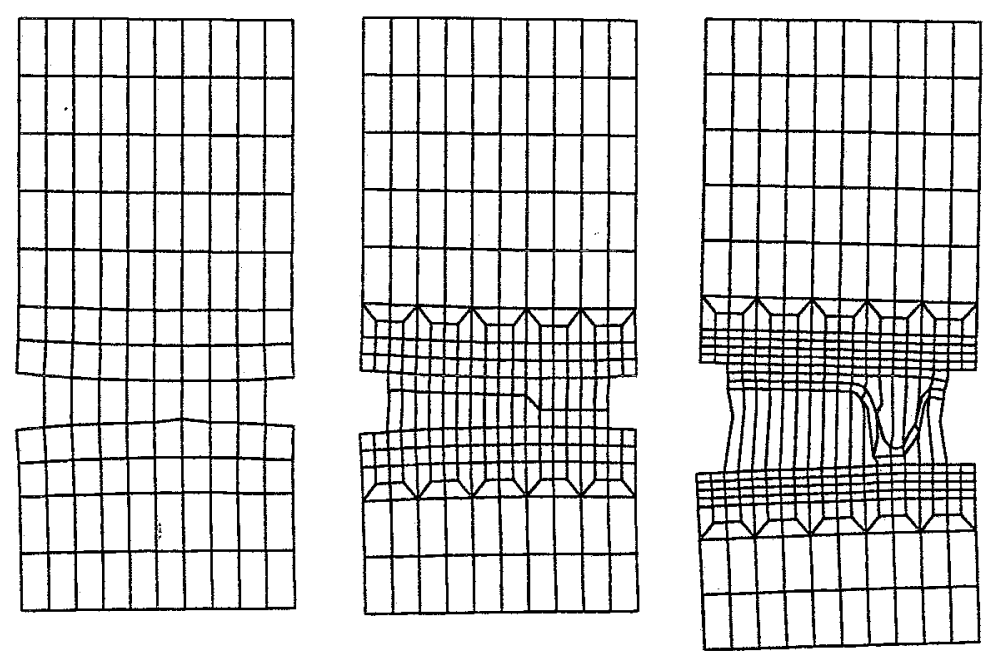

Fig. 2. Displacements of concrete specimen $\left(t=0.50 \cdot 10^{-3} \mathrm{~s}\right)$.

and adding higher-order terms a number of authors [2-4] have proposed to regard the area under the softening curve as a material parameter, namely the fracture energy $G_{\mathrm{f}}$ :

$$
G_{\mathrm{f}}=\int \sigma \mathrm{d} u=\int \sigma \varepsilon(s) \mathrm{d} s .
$$

Assuming a constant softening modulus $h$ and adopting a constant strain distribution over the band, we now obtain that

$$
\frac{\dot{u} / L}{\dot{\sigma}}=\frac{1}{E}+\frac{2 G_{\mathrm{f}}}{L f_{\mathrm{t}}^{2}}
$$

which shows that the solution in the post-peak regime is now only dependent upon the Young's modulus $E$, the fracture energy $G_{\mathrm{f}}$, the tensile strength $f_{\mathrm{t}}$, and the length of the bar $L$. When we prescribe the fracture energy $G_{\mathrm{f}}$ as an additional material parameter the global load-displacement response can become insensitive to the discretisation. However, locally nothing has altered and localisation still takes place in one row of elements. This is logical, since the loss of ellipticity occurs at a local level, even though the energy that is dissipated remains constant by adapting the softening modulus to the element size. For numerical simulations this implies for instance that severe 

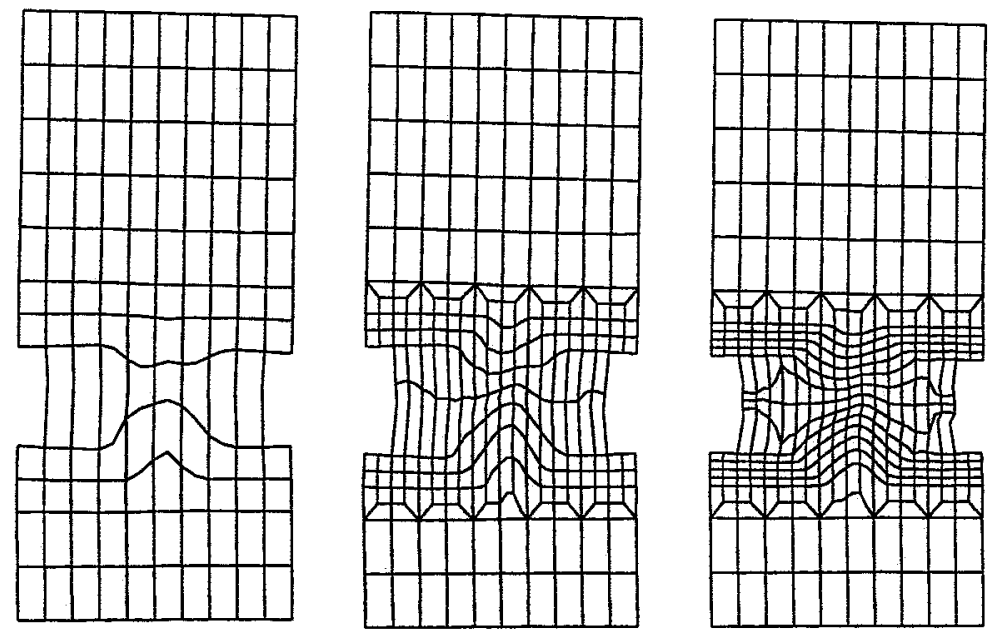

Fig. 3. Displacements for rate-dependent analysis at $t=0.45 \cdot 10^{-3} \mathrm{~s}$.

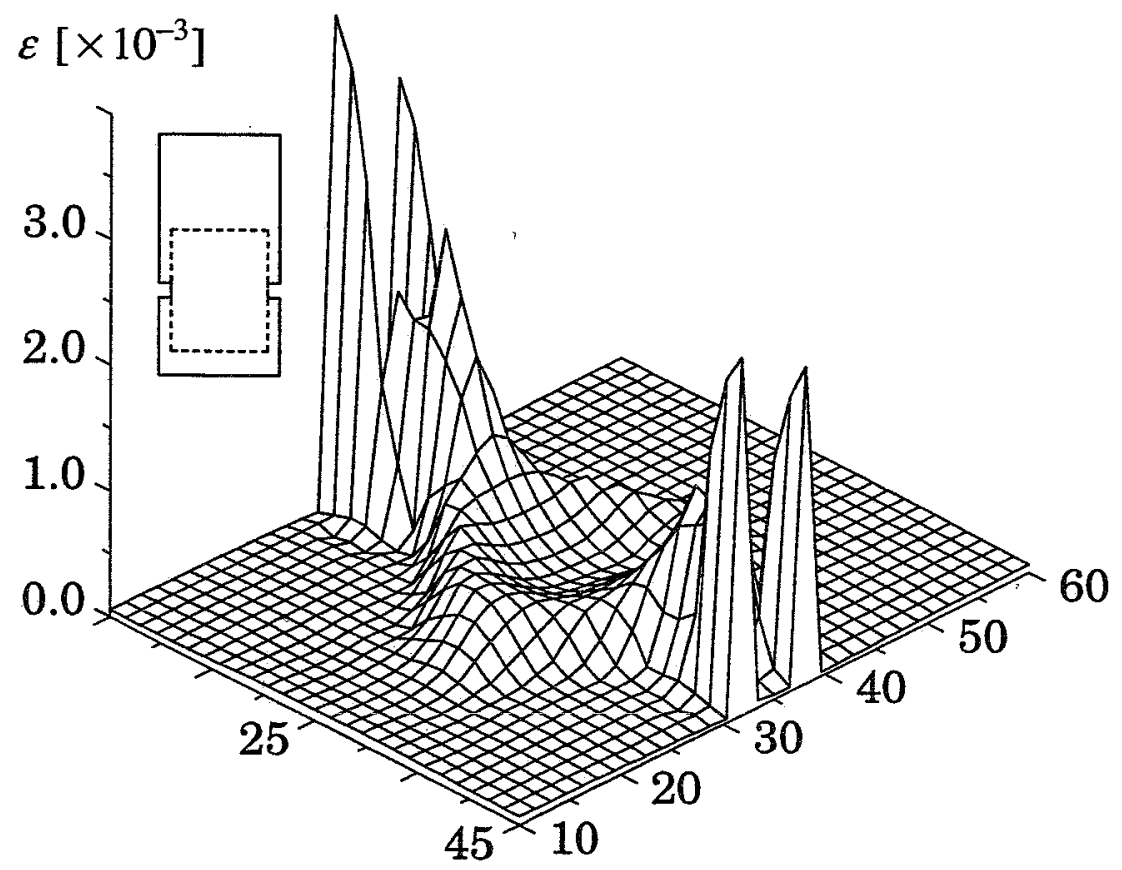

Fig. 4. Axial strain profile in the notched area at $t=0.45 \cdot 10^{-3} \mathrm{~s}$.

convergence problems are usually encountered if the mesh is refined or if in addition to matrix failure interface debonding between matrix and fibres is modelled by inserting interface elements in the numerical model. Also, the frequently reported observation still holds that the localisation zones are biased by the discretisation and tend to propagate along the mesh lines. This can be nicely demonstrated with the example of impact loading a concrete specimen in a Split-Hopkinson device, Figure 1 [5]. The results for the deformed specimen at failure are shown in Figure 2 for three different discretisations in the region between the notches. We observe a clear spurious localisation pattern with the localisation concentrated in a single band of elements which generally follows the mesh lines and occasionally jumps from one row to the next and back without any physical motivation. 


\subsection{Rate-dependent continuum models}

From a physical point of view the introduction of rate dependence is perhaps the most natural way to regularise ill-posed initial value problems which arise because of the introduction of damage or frictional effects. Here we adopt a simple, linear rate-dependent smeared crack model as developed by Sluys [5]. In it the major principal stress degrades according to

$$
\sigma=f_{\mathrm{t}} h \varepsilon^{\mathrm{i}}+m \frac{\partial \varepsilon^{\mathrm{i}}}{\partial t}
$$

with $\varepsilon^{i}$ the inelastic strain, $h$ the softening modulus and $m$ a rate-sensitivity parameter.

Using the rate-dependent smeared crack model as defined in eq. (3) the experiment of a concrete specimen under impact loading in a Split-Hopkinson bar (cf. Figures 1 and 2) has been reanalysed. The incremental displacement patterns are shown in Figure 3. The most striking difference with the displacement pattern of Figure 2 is that localisation now does not proceed along the element lines and is no longer confined to the rows of elements between the notches. This is even more obvious when the strains in the vertical direction are plotted $\left(\varepsilon_{y y}\right)$ as has been done in Figure 4 . We observe a clear branching of the cracks.

\subsection{Non-standard continuum models}

The deficiency of the standard continuum model with regard to properly describing strain localisation can also be overcome by introducing higher-order terms in the continuum description, which are thought to reflect the microstructural changes that take place at a level below the continuum level. Examples of such changes are void formation in metals and crack bridging phenomena in the context of concretes [6]. Essentially, one then departs from the concept of a 'simple' solid which has been the starting point for virtually all modern developments in continuum mechanics. A number of suggestions have been put forward for non-standard continuum descriptions that are capable of properly incorporating failure zones. These include the non-local models $[7,8]$, the use of the Cosserat continuum [9-11] and the gradient models [11-16].

Non-local models can either be introduced in a plasticity-based formalism or in a damage-based format. The latter approach has gained most popularity. In fact, it has been shown in [17] that non-local plasticity models are extremely difficult to implement properly. Non-local damage theory follows standard elasticity-based damage mechanics in that it introduces an internal variable, the damage parameter $\omega$, which accounts for degradation of the elastic stiffness matrix D:

$$
\boldsymbol{\sigma}=(1-\omega) \mathbf{D}^{\mathrm{e}} \boldsymbol{\varepsilon}
$$

In this isotropic elasticity-based damage theory the damage variable $\omega$ grows from zero to one (complete loss of integrity). Damage growth is possible if the 
damage loading function

$$
f(\tilde{\varepsilon}, \kappa)=\tilde{\varepsilon}-\kappa .
$$

vanishes. In particular, the damage loading function $f$ and the rate of damage growth $\dot{\omega}$ have to satisfy the discrete Kuhn-Tucker conditions

$$
f \leq 0, \dot{\omega} \geq 0, f \dot{\omega}=0 .
$$

In (5) $\tilde{\varepsilon}$ is the equivalent strain, which can be a function of the strain invariants, the principal strains as in Mazars [18,19]:

$$
\tilde{\varepsilon}=\sqrt{\sum_{i=1}^{3}\left(<\varepsilon_{i}>\right)^{2}}
$$

with $\varepsilon_{i}$ the principal strains, and $\left\langle\varepsilon_{i}\right\rangle=\varepsilon_{i}$ if $\varepsilon_{i}>0$ and $\left\langle\varepsilon_{i}\right\rangle=0$ otherwise, or the local energy release due to damage. The parameter $\kappa$ starts at a damage threshold level $\kappa_{0}$ and is updated by the requirement that during damage growth $f=0$. Damage growth occurs according to an evolution law $F(\tilde{\varepsilon})$ such that

$$
\omega=F(\tilde{\varepsilon}) .
$$

The salient departure from the local damage theory occurs when the local damage parameter $\omega$ in the above identities is replaced by an averaged or non-local value $\bar{\omega}$, such that

$$
\bar{\omega}(\mathbf{x})=\frac{1}{V_{g}} \int_{V} \omega(\mathbf{x}+\tau) g(\tau) \mathrm{d} V \quad, \quad V_{g}=\int_{V} g(\tau) \mathrm{d} V
$$

with $\tau$ the separation vector between the points $\mathbf{x}$ and $\mathbf{x}+\tau$, and $g$ an attenuating weighting function, e.g., the error function

$$
g(\tau)=\exp \left(-|\tau|^{2} / 2 l^{2}\right)
$$

in which the non-local parameter $l$ has the role of an internal length scale.

Non-local damage theory suffers from the drawback that the issue of additional boundary conditions for this higher-order continuum is still not completely settled, thus rendering the theory incomplete. Also, they seem less amenable to an efficient implementation, thus making large-scale computations less feasible. It is for these reasons that gradient models, in which the higher-order gradients of internal parameters are considered instead of averaging one or more internal parameters, are here considered as a serious alternative for non-local approaches.

Below we shall restrict ourselves to a brief discussion and an example of a gradient-enhanced Rankine flow plasticity theory [20-22]. The essential feature of gradient plasticity theory is that the yield function $f$ not only depends upon the stress $\sigma$ and an equivalent inelastic strain measure $\gamma^{i}$, but that there is also a dependence upon gradients of $\gamma^{\mathrm{i}}$, e.g., the Laplacian:

$$
f=f\left(\sigma, \gamma^{\mathrm{i}}, \nabla^{2} \gamma^{\mathrm{i}}\right) \text {. }
$$




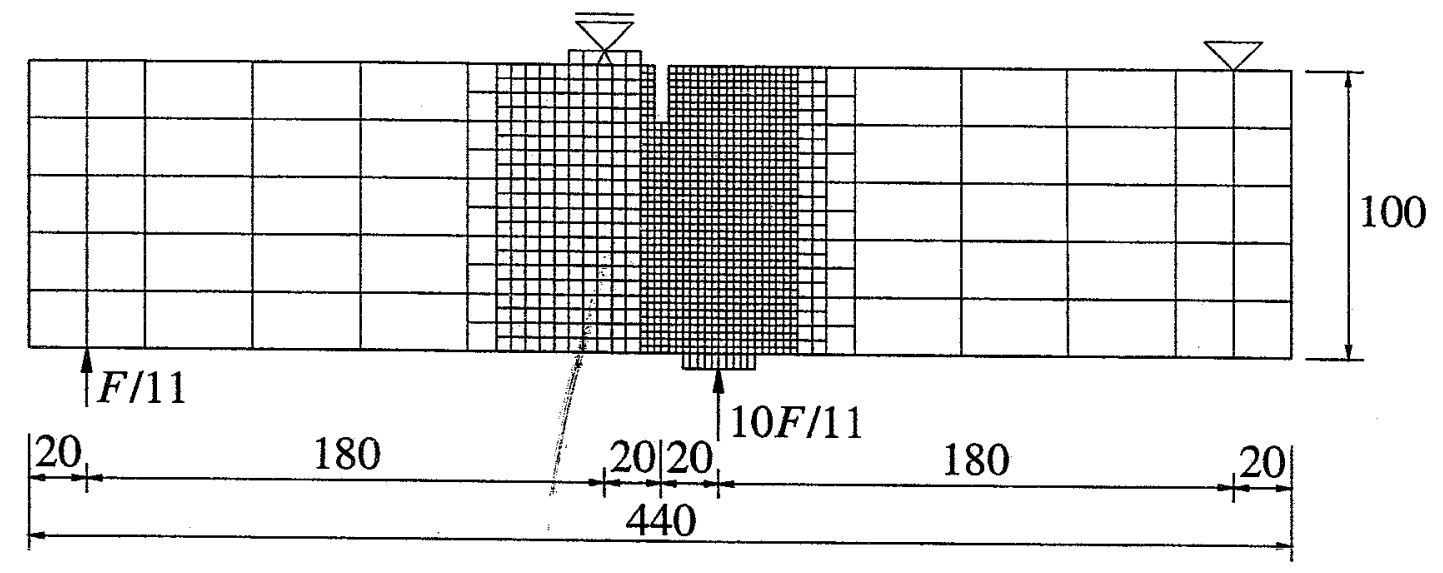

Fig. 5. Loading configuration and discretisation of SEN beam.
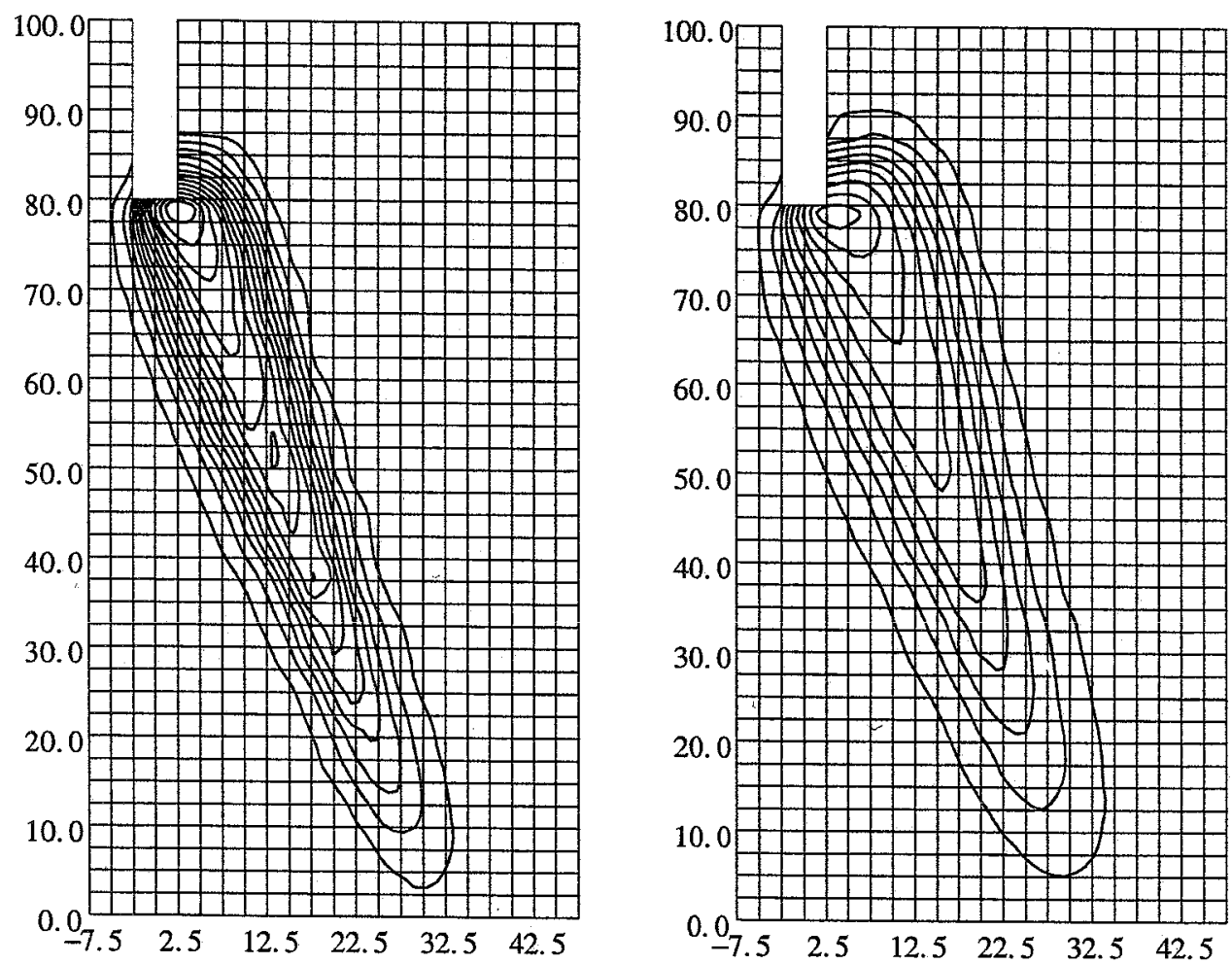

Fig. 6. Contour plots of equivalent fracture strain at the final load level for $l=2 \mathrm{~mm}$ (left) and $l=3 \mathrm{~mm}$ (right).

If we denote by $\sigma_{1}$ the major principal stress and by $\bar{\sigma}$ the instantaneous tensile strength, then

$$
f=\sigma_{1}-\bar{\sigma}\left(\gamma^{\mathrm{i}}, \nabla^{2} \gamma^{\mathrm{i}}\right) .
$$

When it is further assumed that the dependence upon the gradient term is linear - the simplest possible case - then eq. (12) reduces to

$$
f=\sigma_{1}-\bar{\sigma}\left(\gamma^{\mathrm{i}}\right)-\bar{c} \nabla^{2} \gamma^{\mathrm{i}}
$$

In the example calculations that will be presented below $\bar{c}$ has been taken 
proportional to the rate of softening: $\bar{c}=l^{2} \partial \bar{\sigma} / \partial \gamma^{\mathrm{i}}$. The material parameter $l$ has the dimension of length and represents the gradient influence. For $l=0$ the standard Rankine flow theory is recovered.

The gradient-dependent Rankine plasticity model has been applied to mixed-mode crack propagation in a Single-Edge Notched plain concrete beam (Iosipescu geometry). The experimental resuls are from Schlangen [23]. The loading configuration including some aspects of the numerical discretisation is shown in Figure 5. The loading plates have been included in the discretisation and have also been modelled with reduced integrated eight-noded quadrilaterals, but with a higher stiffness. Details of the employed mixed finite element formulation are given in [21,22].

The material data for the concrete, determined as the average experimental values are: Young's modulus $E=35 \mathrm{GPa}$, Poisson's ratio $v=0.2$, the tensile strenth $f_{\mathrm{t}}=3.0 \mathrm{MPa}$ and fracture energy $G_{\mathrm{f}}=0.1 \mathrm{~N} / \mathrm{mm}$. For this value of the fracture energy two different length scales $l$ have been considered, namely $l=3 \mathrm{~mm}$ and subsequently $l=2 \mathrm{~mm}$. The differences with respect to the width of the fracture process zone are shown in the contour plots of the equivalent fracture strain of Figure 6. Provided that the fracture energy is kept constant a variation of the internal length parameter $l$ does, however, not affect the load-CMSD diagrams shown in Figure 7, neither does the discretisation influence the results for this level of mesh refinement. Since the computed load-CMSD diagram is too brittle compared with the experiment another analysis with a higher value of the fracture energy $(0.2 \mathrm{~N} / \mathrm{mm})$ has also been conducted, Figure 7.

\section{Stochastic methods and damage evolution}

A fundamental question regarding application of random fields to localisation phenomena is whether a statistical description of the standard continuum resolves the ill-posedness that arises after the onset of localisation. This question becomes imperative especially if we consider that the description of a heterogenous continuum by correlated random variables introduces a length parameter in the form of the correlation length $\theta$ analogous to the introduction of an internal length scale $l$ in non-standard continua. The correlation length $\theta$ is a measure for the rate of fluctuations of the random field and may significantly influence the damage process and global response of the structure. The example of a tensile specimen with random initial damage is well suited to study this fundamental issue. We assume that the initial damage threshold is randomly distributed over the solid and can be represented by a non-Gaussian correlated random field. For the non-Gaussian field a threeparameter Weibull distribution function is assumed:

$$
f\left(K_{0}\right)=\lambda \mu\left(K_{0}-K_{0}^{\min }\right)^{\mu-1} \exp \left[-\lambda\left(K_{0}-K_{0}^{\min }\right)^{\mu}\right]
$$

with $\lambda, \mu$ the Weibull-parameters and $K_{0}^{\mathrm{min}}$ the lower bound of the initial damage threshold. The material parameters are taken from Carmeliet [24] and 
Force $[\mathrm{kN}]$

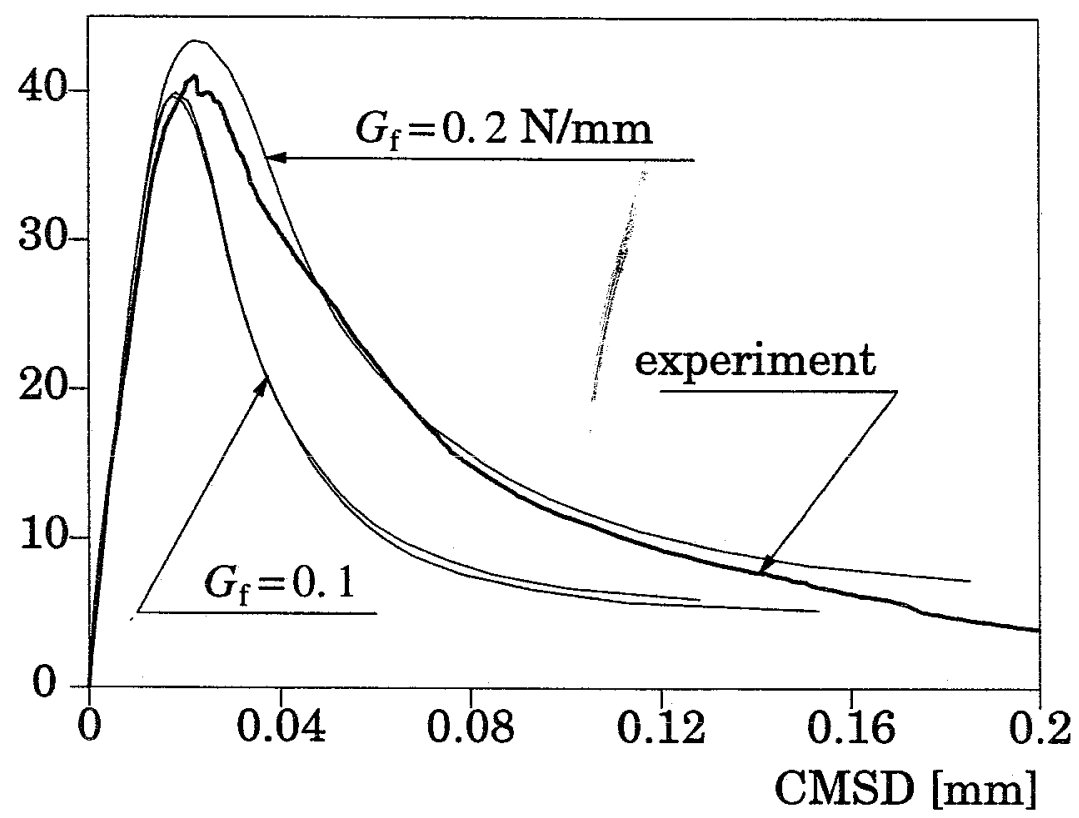

Fig. 7. Computed and experimentally obtained load-CMSD diagrams.

have been assigned the following values: $\lambda=6.56 \cdot 10^{5}, \quad \mu=1.6$, $K_{0}^{\min }=0.66 \cdot 10^{-4}$. An inverse fitting procedure, comparing the numerical responses to the experimental distribution of tensile strength and energy dissipation, was used for the proper identification of the material parameters [24]. The field is assumed to be homogeneous and isotropic, which implies that the autocorrelation coefficient function can be expressed in terms of the separation vector $\tau$ between the points $\mathbf{x}$ and $\mathbf{x}+\tau$. The autocorrelation coefficient function is assumed to be of the same form as the weight function of the nonlocal damage model:

$$
\rho(\tau)=\exp \left(-|\tau|^{2} / 2 d^{2}\right)
$$

with $d$ a parameter. In case of a squared exponential function as in eq. (15) $d$ is related to the correlation length $\theta$ by $d=\theta / \sqrt{2}$. The correlation length $\theta$ is defined here as the length over which the autocorrelation coefficient function drops to a small value, say $\mathrm{e}^{-1}$. In the simulations the correlation parameter has been assigned the value $d=5 \mathrm{~mm}$ or, equivalently, a correlation length $\theta$ $=7 \mathrm{~mm}$.

For the finite element discretisation two different meshes have been used: $8 \times 32$ and $16 \times 64$ elements. During the discretisation process, the size of the stochastic element is not changed. This means that a stochastic element is either a block of one or of four finite elements with identical random properties. Furthermore, we assume a constant linear softening diagram with a softening modulus $h=-0.1 E$ and an elastic modulus $E=20000 \mathrm{MPa}$.

The differences between the local and nonlocal stochastic models become most clear when comparing the total energy dissipation during damage for the two different finite element discretisations. Figure 8 shows the cumulative distributions calculated from the responses of 100 samples using the 


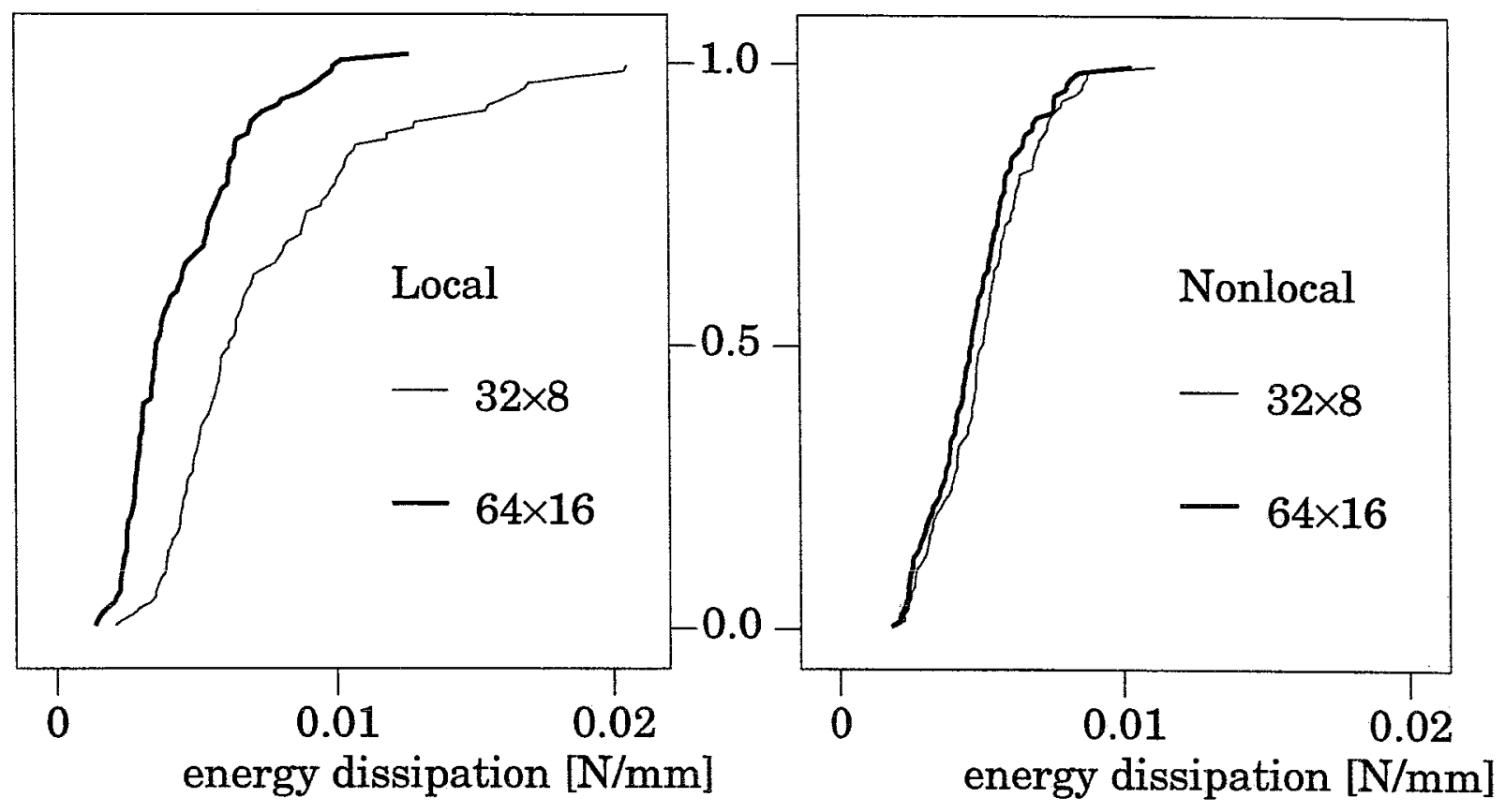

Fig. 8. Cumulative distribution of the energy dissipation during failure. Left: local damage model. Right: non-local damage model.

Monte Carlo technique. The results for the local damage model, obtained for a less steep softening branch, $h=-0.01 E$, are clearly mesh dependent: a decreasing energy dissipation is observed upon mesh refinement. On the contrary, the results for the nonlocal stochastic model show a perfect agreement for both discretisations. These observations correspond fully with the findings for deterministic models.

So far, we have shown that a stochastic continuum description of damage localisation must include a regularisation technique to prevent loss of wellposedness of the rate boundary value problem. A major problem now lies in combining the two different length parameters introduced in a physically realistic manner: the internal length scale $l$ of the nonlocal continuum and the correlation length $\theta$ of the random field. Both length parameters result from the transition of a micro-level to a macro continuum level. While the internal length $l$ depends merely on the typical size of defects (or aggregates), the correlation length $\theta$ depends on the size as well on the frequency, i.e. the distance between successive defects.

\section{Some reflections on future work}

In this contribution current developments have been reviewed for modelling localisation and fracture via continuum methods. Various promising approaches exist, but there is no such a thing like a panacea which cures the shortcomings of standard, rate-independent continua upon the introduction of strain softening and/or non-symmetry in the constitutive rate equations.

In the authors' opinion the most pressing issues that require further at- 
tention for failure computations are:

- The proper determination of the additional model parameters that emerge in the higher-order and rate-dependent continuum models when compared to the classical approach. Especially in higher-order continua this problem is not solved easily, since the additional parameters are not directly derivable from elementấry tests such as uniaxial or triaxial tension or compression tests. Even if one would be able to carry out a test on a perfect specimen, so that homogeneous deformations would occur throughout the entire loading programme, these parameters could not be measured because for homogeneous deformations there is no effect of the higher-order continuum models. Therefore, one must proceed in a semi-inverse manner, whereby the experimental results of different types of tests are fitted in the post-peak regime.

- The steep strain gradients that occur in higher-order and ratedependent continua during failure require that very fine meshes are used to capture the failure mode properly. If such analyses are to be carried out on nowadays' or even tomorrow's computers, then the use of adaptive mesh refinement techniques or spectral overlay methods is a conditio sine qua non. A problem is the development of proper criteria for mesh refinement in inelastic, non-standard continua. Although necessary this will probably not prove an easy task.

- The proper combination of stochastic methods with higher-order continuum models for frictional and damaging materials.

\section{Acknowledgements}

Financial support of the Commission of the European Communities through the Brite-EuRam programme (project BE-3275) and the Human Capital and Mobility Programmes (A.L.E.R.T. Geomaterials), and the Netherlands Academy of Arts and Sciences is gratefully acknowledged.

\section{References}

[1] de Borst, R. (1986) Non-linear analysis of frictional materials, Dissertation, Delft University of Technology, Delft.

[2] Bazant, Z.P. and Oh, B. (1983) Crack band theory for fracture of concrete. Materials and Structures, Vol. 16, 155-177.

[3] Pietruszczak, S. and Mróz, Z. (1981) Finite element analysis of deformation of strain softening materials. Int. J. Num. Meth. Eng., Vol. 17, 327-334.

[4] Willam, K. (1984) Experimental and computational aspects of concrete fracture, in Proc. Int. Conf. Computer Aided Analysis and Design of Concrete Structures, (eds. F. Damjanić et al.), Pineridge Press, Swansea, pp. 33-70.

[5] Sluys, L.J. (1992) Wave propagation, localisation and dispersion in softening solids, Dissertation, Delft University of Technology, Delft, 1992.

[6] van Mier, J.G.M. (1991) Mode-I fracture of concrete: discontinuous crack growth and 
crack interface grain bridging. Cement and Concrete Research, Vol. 21, 1-15.

[7] Pijaudier-Cabot, G. and Bazant, Z.P. (1987) Nonlocal damage theory. ASCE J. Eng. Mech., Vol. 113, 1512-1533.

[8] Bazant, Z.P. and F.B. Lin (1988) Non-local yield limit degradation. Int. J. Num. Meth. Eng., Vol. 26, 1805-1823.

[9] Mühlhaus, H.-B. and Vardoulakis, I. (1987) The thickness of shear bands in granular materials. Geotechnique, Vol. 37, 271-283.

[10] de Borst, R. (1991) Simulation of strain localisation: A reappraisal of the Cosserat continuum. Eng. Comp., Vol. 8, 317-332.

[11] de Borst, R. (1993) A generalisation of $J_{2}$-flow theory for polar continua. Comp. Meth. Appl. Mech. Eng., Vol. 103, 347-362.

[12] Aifantis, E.C. (1984) On the microstructural original of certain inelastic models. J. Eng. Mat. Technol., Vol. 106, 326-334.

[13] Schreyer, H.L. and Chen, Z. (1986) One-dimensional softening with localization. ASME J. Appl. Mech., Vol. 53, 791-979.

[14] Lasry, D. and Belytschko, T. (1988) Localization limiters in transient problems. Int. J. Solids Structures, Vol. 24, 581-597.

[15] Mühlhaus, H.-B. and Aifantis, E.C. (1991) A variational principle for gradient plasticity. Int. J. Solids Structures, Vol. 28, 845-858.

[16] de Borst, R. and Mühlhaus, H.-B. (1992) Gradient-dependent plasticity: Formulation and algorithmic aspects. Int. J. Num. Meth. Eng., Vol. 35, 521-539.

[17] de Borst, R., Sluys, L.J., Pamin, J. and Mühlhaus, H.-B. (1993) Fundamental issues in finite element analyses of localisation of deformation. Eng. Comp., Vol. 10, 99-121.

[18] Mazars, J. (1984) Application de la mécanique de l'endommagement au comportement non linéare et à la rupture du béton de structure, These d'Etat, Université Paris VI, Paris.

[19] Mazars, J. and Pijaudier-Cabot, G. (1989) Continuum damage theory - application to concrete. ASCE J. Eng. Mech., Vol. 115, 345-365.

[20] Pamin, J. (1993) Mesh sensitivity in gradient dependent softening plasticity: II. Application of Rankine and Drucker-Prager yield criteria, Report 25-2-93-2-14, Delft University of Technology, Delft.

[21] Pamin, J. (1993) Mesh sensitivity in gradient dependent softening plasticity: III. Finite element formulations, Report 25-2-93-2-15, Delft University of Technology, Delft.

[22] Pamin, J. and de Borst, R. (1994) Gradient plasticity and finite elements in the simulation of concrete fracture, in Computational Modelling of Concrete Structures, (eds. H. Mang, N. Bicanić and R. de Borst), Pineridge Press, Swansea, pp. 393-402.

[23] Schlangen, E. (1993) Experimental and numerical analysis of fracture processes in concrete, Dissertation, Delft University of Technology, Delft.

[24] Carmeliet, J. (1992) Durability of fiber-reinforced renderings for outside insulation: a probabilistic approach based on the nonlocal continuum damage mechanics (in Dutch), Dissertation, Catholic University of Leuven, Leuven. 